\title{
Development and Characterization of EST-SSR Markers for Juniperus squamata (Cupressaceae), an ecologically important conifer in Asian mountains
}

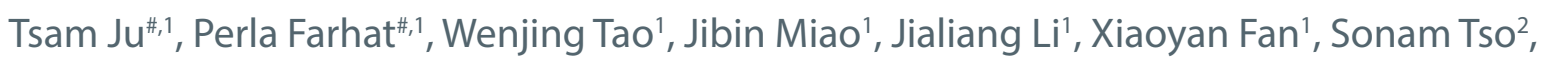 \\ Kangshan Mao*,1
}

\begin{abstract}
${ }^{1}$ Key Laboratory of Bio-Resource and Eco-Environment of Ministry of Education, College of Life Sciences, Sichuan University, Chengdu, 610065, People's Republic of China;

${ }^{2}$ College of Science, Tibet University, Lhasa 850000, Tibet, P.R. China.

" These authors contributed equally to this work.
\end{abstract}

*Corresponding author: Kangshan Mao, E-mail: maokangshan@163.com

\begin{abstract}
Juniperus squamata, an endemic conifer of Asia, is an important shrub ecologically and economically. Yet little is known about its genetic diversity and population structure due to lacking of highly polymorphic molecular markers. In this study, expressed sequence tag microsatellite markers (EST-SSR) were developed for Juniperus squamata. Illumina HiSeq data were used to reconstruct the transcriptome of this species by de novo assembly. Based on this transcriptome, 18 SSR markers were designed and successfully amplified. Just one locus was eliminated due to its detection of null alleles and the remaining 17 loci were polymorphic, generating five to 14 alleles per locus in J. squamata. Markers cross-amplification tests were successful in two closely related species of J. squamata. These markers will serve as a basis for further studies to assess the genetic diversity and population structure of J. squamata. As well, they could be useful in promoting sustainable forest management strategies for this species in the face of global climate change.
\end{abstract}

Keywords: : Cupressaceae; microsatellite marker; Juniperus squamata; Juniperus tibetica; Juniperus saltuaria; transferability

\section{Introduction}

Juniperus squamata Buch.-Ham. is an evergreen coniferous shrub or small tree belonging to the Cupressaceae family (Adams, 2014). This species is native to Asia and has been found to be widespread in China, Bhutan, North India, Myanmar, Afghanistan and Pakistan (Farjon, 2005; Adams, 2014). It is found in forests, thickets, valleys and roadsides of the mountain areas at altitudes ranging from 1340 to 4850 meters a.s.l. (Farjon, 2005; Adams, 2014). Being frequently the only subalpine and alpine coniferous shrub species able to grow in semiarid environments, J. squamata presents an essential ecological value in mountainous ecosystems, especially for soil and water conservation, as well as a shelter and food source to some birds and other animal species (Chen et al., 2015). Besides its ecological importance, J. squamata showed a great economical value as an ornamental shrub widely cultivated in Europe and North America (Farjon, 2005). Two varieties are recognized for this dioecious species, J. squamata var. squamata, and J. squamata var. wilsonii (Rehder) R.P. Adams. Minor phenotypic variations were reported between these two varieties, especially in their foliage and seed cones (Adams, 2014). To date, apart from some basic taxonomic data (Adams, 2014), little is known on the genetic diversity and population structure of this species. However, these genetic parameters are essential for a better understanding of the species' response to climate change and for further sustainable management strategies. Pauls et al. (2018) showed that climate change may 
affect genetic diversity; populations may suffer from habit loss and fragmentation, and become strongly inbred and prone to genetic drift due to smaller effective population size, causing dramatic increase in stress sensitivity and thus enhance extinction risk. It is clear that the overall level of genetic diversity will likely drop in many populations and species affected by climate change events (Pauls et al., 2013), especially in mountainous areas with high elevation such as the Qinghai-Tibet Plateau (Pepin et al., 2015). In contrast, in some cases, climate change would potentially increase the genetic diversity in plants. In fact, environmental change was defined as an efficient force to hybrid formation and hybrid speciation due to its effect on the distribution ranges of plants (Vallejo and Hiscock, 2016; Klonner et al., 2017; Chunco 2014; Gómez et al., 2015), leading to an increase in the genetic diversity.

In the last decade, simple sequence repeat (SSR) markers, also known as short tandem repeats or microsatellites, were largely employed in plant genetic studies (Vieira et al., 2016). Indeed, these markers were shown to be highly polymorphic which explains their great usefulness in population genetic analysis (Zhang et al., 2012; Jiang et al., 2015). Despite their importance, the biggest limitation of microsatellites resides in the traditional development of these markers for non-model species (Miah et al., 2013), which is the case of Juniperus (Douaihy et al., 2011). Therefore, recent technologies such as transcriptome sequencing were demonstrated to be advantageous tools (powerful and cost-effective) for molecular markers development including SSRs, particularly in non-model species (Ashrafi et al., 2012; Qi et al., 2016; Li et al., 2019).

In this study, we aimed to develop a set of expressed sequence tag (EST) SSR markers for J. squamata through transcriptome assembling for further population genetic studies. Also, we tested the transferability of these markers to closely related Juniperus species, J. tibetica Kom. and J. saltuaria Rehder \& E. H. Wilson.

\section{Materials and Methods}

\section{Plant material}

Leaf samples from 113 individuals of $J$. squamata, 11 individuals of $J$. tibetica and 13 individuals of $J$. salutaria were collected from three populations of each species (Appendix 1). For each individual, fresh leaves were collected and dried immediately in silica gel and then stored at room temperature. For transcriptome sequencing, fresh leaves of one individual from Kangding, Sichuan Province, China (geographic coordinates: N $30^{\circ} 00.31^{\prime}$, E $101^{\circ} 52.12^{\prime}$ ) were collected and frozen immediately in liquid nitrogen, and then stored at $-80^{\circ} \mathrm{C}$ until analysis. The geographic coordinates and elevations of all studied populations were measured using an Etrex GIS (Garmin, Taiwan, China).

\section{Transcriptome sequencing and SSR markers detection}

Around $10 \mu \mathrm{g}$ of total RNA was extracted from fresh leaves of one J. squamata individual using TRIzol Reagent (Invitrogen, Carlsbad, California, USA). This was followed by the isolation and fragmentation of mRNA using the magnetic oligo (dT) beads (Illumina, San Diego, California, USA) and the Ambion RNA Fragmentation (Ambion, Austin, Texas, USA) Kits, respectively. The first-strand cDNA was synthesized using reverse transcriptase (Invitrogen) and random primers, whereas, the second-strand was elaborated by RNase $\mathrm{H}$ and DNA Polymerase I (Invitrogen). Transcriptome sequencing was performed on an Illumina HiSeq 2000 system at Novogene (Beijing, China). Sequences were filtered and clean reads were de novo assembled by Trinity v2.8.5 software (Grabherr et al., 2011).

Microsatellite markers were detected using the Perl script MISA (Thiel et al., 2003) with motifs of one to six nucleotides and the threshold repeat unit defined as eight for mono-, four for di- and tri- and three for tetra-, penta-, and hexanucleotides. On this basis, primer pairs were designed for detected markers using Primer3 v.2.3.6 (Rozen and Skaletsky, 2000; Untergasser et al., 2012) implemented in the QDD software (Meglecz et al., 2014). The following tasks are completed by QDD software: tag sorting, adapter/vector removal, elimination of redundant sequences, detection of possible genomic multi-copies (duplicated loci or transposable elements), stringent selection of target microsatellites and customizable primer design. After a random browsing across the output files, 40 markers were selected based on the length (19-20 bp), GC content (40-65 \%) and annealing temperatures $\left(53-57^{\circ} \mathrm{C}\right)$ of their primer sets. Detected loci were filtered through BLAST with an E-value of $1 \mathrm{E}-40$ to remove redundancy.

\section{SSR markers amplification and characterization}

The genomic DNA was extracted from dried leaves of all sampled J. squamata, J. tibetica and J. salutaria individuals following the modified cetyltrimethylammonium bromide (CTAB) method (Doyle and Doyle, 1987; Tsumura et al., 1995). PCR reactions were executed in a final volume of $25 \mu \mathrm{L}$. Each reaction contained $12.50 \mathrm{uL} 2 \times$ PCR buffer, $300 \mu \mathrm{M}$ of each dNTPs, $0.3 \mu \mathrm{M}$ of each forward and reverse primer, 1.25 unit of Taq DNA polymerase (Vazyme Biotech, Nanjing, China), and ca. 50 ng of genomic DNA. PCR amplifications were performed using the cycling parameters: initial denaturation step at $98^{\circ} \mathrm{C}$ for $3 \mathrm{~min}$, followed by 40 cycles at $98^{\circ} \mathrm{C}$ for $10 \mathrm{~s}$, annealing temperatures of the primer pair for $30 \mathrm{~s}, 72^{\circ} \mathrm{C}$ for $45 \mathrm{~s}$; and a final extension step at $72^{\circ} \mathrm{C}$ for $10 \mathrm{~min}$. The PCR products were checked for their success on $1 \%$ agarose gel and then sent for microsatellites genotyping. Each forward primer used in this study was labeled with either FAM, TAMRA, HEX, and ROX (Applied Biosystems, Foster City, California, USA) at the 5 ' extremity (Table 1) to allow fragment detection on the ABI PRISM 3100 genetic analyzer. The microsatellite genotype at each locus for each individual was determined using GeneMapper v.4.1 (Soft Genetics, State College, Pennsylvania, USA). For each locus, allele sizes were scored and checked for genotyping errors such as stuttering, large allele dropouts and null alleles, using CERVUS3.0 software (http://helios.bto.ed.ac.uk/evolgen) (Marshall et al.,1998; Dakin and Avise, 2004). Using this software, allele frequency analysis module can carry out Hardy-Weinberg equilibrium detection and invalid allele frequency calculation. The software uses the method proposed by Summers 
Table 1

Characteristics of the 18 microsatellite markers developed for Juniperus squamata.

\begin{tabular}{|c|c|c|c|c|c|c|c|c|c|c|}
\hline Locus & Primer sequence (5'-3') & $\begin{array}{l}\text { Repeats } \\
\text { motif }\end{array}$ & $\begin{array}{l}\text { Allele size } \\
\text { (bp) }\end{array}$ & $T_{a}\left({ }^{\circ} \mathrm{C}\right)^{\mathrm{a}}$ & $\begin{array}{l}\text { Fluorescent } \\
\text { dye }\end{array}$ & $r$ & $\begin{array}{l}\text { GenBank } \\
\text { accession no. }\end{array}$ & Protein $^{b}$ & Organism $^{\mathrm{c}}$ & E-value $^{d}$ \\
\hline \multirow[t]{2}{*}{ HEX-25 } & F:TGCTGGCTGTTGACATTCTC & $(\mathrm{TA})_{7}$ & 268 & 55 & HEX & 0.2121 & BT107955 & Unknown & Picea glauca & $1 \times 10^{-144}$ \\
\hline & R:GCCGCTCTTCAAACTAGCAC & & & & & & & & & \\
\hline \multirow[t]{2}{*}{ FAM-26 } & F:CATGATGTGTTCCCAACTGC & $(\mathrm{TA})_{7}$ & 399 & 55 & FAM & 0.0889 & XM_022045498 & XP_021901190.1 & Carica papaya & $1 \times 10^{-125}$ \\
\hline & R:GGAGGTCTTGGGTTCGAGTT & & & & & & & & & \\
\hline \multirow[t]{2}{*}{ FAM-36 } & F:AGTGTTGTTTTGACCCCAGC & $(\mathrm{CAT})_{7}$ & 257 & 55 & FAM & 0.2694 & XM_010934704 & XP_010933006.1 & Elaeis guineensis & $5 \times 10^{-19}$ \\
\hline & R:GGTTTTGGGATCAATGGTTG & & & & & & & & & \\
\hline \multirow[t]{2}{*}{ HEX-43 } & F:CTGCTGGATGCAAACTTCAA & $(\mathrm{ATA})_{6}$ & 314 & 55 & HEX & -0.0006 & BT105738.1 & & Picea glauca & 0 \\
\hline & R:TCCGAAACAGAGCTTGGACT & & & & & & & & & \\
\hline \multirow[t]{2}{*}{ HEX-65 } & F:CACCATTTTTGCAGGGAGTT & $(\mathrm{TTG})_{6}$ & 358 & 55 & HEX & 0.0626 & KJ664363.1 & AIF28376.1" & Thuja plicata & 0 \\
\hline & R:GGGGTTGTATAATGCCCAGA & & & & & & & & & \\
\hline \multirow[t]{2}{*}{ HEX-68 } & F:CTAAAACCATTGGACTGGCG & $(\mathrm{TTC})_{7}$ & 342 & 55 & HEX & 0.0235 & AK406832.1 & & Cryptomeria japonica & 0 \\
\hline & R:AAACAAAACCCTACAGGCCC & & & & & & & & & \\
\hline \multirow[t]{2}{*}{ FAM-71 } & F:GGGCATAGGTGTGACGATCT & $(\mathrm{AGG})_{5}$ & 375 & 55 & FAM & -0.0236 & AK406949.1 & & Cryptomeria japonica & 0 \\
\hline & R:ACGGCAAGGAGAAACAGAGA & & & & & & & & & \\
\hline \multirow[t]{2}{*}{ HEX-77 } & F:CCGTTCTCTTTTCCCATGAA & $(\mathrm{AGG})_{5}$ & 327 & 55 & HEX & 0.2784 & Unknown & Unknown & & \\
\hline & R:CTTGCACCACACTCCTCTGA & & & & & & & & & \\
\hline \multirow[t]{2}{*}{ *HEX-97 } & F:CTGAGTGCTCAGACTGCACC & $(\mathrm{TTTC})_{5}$ & 355 & 57 & HEX & 0.4072 & Unknown & Unknown & & \\
\hline & R:CCCTAGTTTGAAGCAACCCA & & & & & & & & & \\
\hline \multirow[t]{2}{*}{ TAMAR-103 } & F:GATTTGCACGCATTACATCG & (CT) 9 & 140 & 53 & TAMAR & -0.0203 & BT119739.1 & & Picea glauca & 0 \\
\hline & R:ATTGTCAAGAATGCTCCCCA & & & & & & & & & \\
\hline \multirow[t]{2}{*}{ TAMAR-116 } & F:TGAAACAGTTGCGAATGAGC & $(\mathrm{AGG})_{7}$ & 211 & 55 & TAMAR & 0.1389 & KY010977.1 & & Chamaecyparis hodginsii & 0 \\
\hline & R:GTCCTTTCCATCTTCTTGCG & & & & & & & & & \\
\hline \multirow[t]{2}{*}{ HEX-123 } & F:TGTTGCCCATTTGCTGATAA & $\left(\mathrm{TAT}_{) 9}\right.$ & 202 & 55 & HEX & 0.0488 & AK415837.1 & & Cryptomeria japonica & $4 \div 10^{-67}$ \\
\hline & R:CAAGGCAACAATCCACACTG & & & & & & & & & \\
\hline \multirow[t]{2}{*}{ TAMAR-134 } & F:TCCCAAATGCATTCATCTCA & $(\mathrm{TAT})_{5}$ & 187 & 55 & TAMAR & 0.0351 & Unknown & Unknown & & \\
\hline & R:TGTGGACTAAGGACGCCAAT & & & & & & & & & \\
\hline \multirow[t]{2}{*}{ CMJ-206 } & F:CTGCCTTTTCAAAGCAGGTC & $(\mathrm{TCT})_{5}$ & 397 & 55 & FAM & 0.0256 & XM_023129194.1 & XP_022984962.1" & Cucurbita maxima & $4^{4 * 10^{-}}$ \\
\hline & R:CTCCTGGCACTTCGAATCTC & & & & & & & & & \\
\hline \multirow[t]{2}{*}{ CMJ-214 } & F:GCAGCTACAACAGCAGCAAG & $(\mathrm{CAG})_{6}$ & 339 & 55 & HEX & -0.2761 & XM_007012516.2 & XP_007012578.2" & Theobroma cacao & 0 \\
\hline & R:GATGGGGCATCTGTTTCAGT & & & & & & & & & \\
\hline \multirow[t]{2}{*}{ CMJ-230 } & F:GATCCATCGTAGGCGTTGTT & $(\mathrm{AAC})_{7}$ & 161 & 55 & FAM & 0.018 & BT115719 & & Picea glauca & 0 \\
\hline & R:GAGGGAGAGCTGCTGAAAGA & & & & & & & & & \\
\hline \multirow[t]{2}{*}{ CMJ-231 } & F:TTGTAAACCTCAACCTCCCG & $(\mathrm{GCA})_{7}$ & 374 & 55 & FAM & 0.0268 & Unknown & Unknown & & \\
\hline & R:CGATTTCCAGTAAGCAAGGC & & & & & & & & & \\
\hline \multirow[t]{2}{*}{ CMJ-241 } & F:CTTGAGGGATTGAAATTGCC & $(\mathrm{TTC})_{5}$ & 347 & 53 & ROX & -0.0379 & KY011071.1 & & Chamaecyparis hodginsii & 0 \\
\hline & R:TTGCAAGAGCACCATCTGAC & & & & & & & & & \\
\hline
\end{tabular}

Note: $r=$ frequency of null alleles.

a The annealing temperature for each primer is listed, and the final annealing temperature for each PCR reaction is given as the average annealing.

${ }^{b}$ Id of the most matching protein to the EST. The data were collected from BLAST analysis.

c Species from which the BLAST match was obtained.

${ }^{\mathrm{d}}$ E-value linked to the BLAST match.

${ }^{*}$ Locus presenting a frequency of null alleles higher than 0.4 . 
and Amos (1997) to calculate invalid allele frequencies through the maximum likelihood method. Finally, we used GenAIEx v.6 (Peakall and Smouse, 2012), to estimate the average number of alleles per locus, the observed heterozygosity $\left(H_{0}\right)$, the expected heterozygosity $\left(H_{e}\right)$, and the deviation of loci from Hardy Weinberg equilibrium (HWE).

\section{Results and discussion}

The transcriptome of $J$. squamata was successfully sequenced and assembled. A total of 3693 SSR motifs were identified by MISA, where trinucleotide repeats were the most abundant type with a frequency of $69.22 \%$, followed by dinucleotide (27.21\%) and tetranucleotide (3.91\%). We randomly selected 20 individuals, and 50 trinucleotide, 40 dinucleotide and 10 tetranucleotide motifs, for a pilot screening of SSR markers. A total of 18 SSR markers were selected based on PCR success rate (amplification success greater than $85 \%$ ) and degree of polymorphism (difference in band length) (Table 1). In total, just one locus (HEX-97) presented null alleles (null allele frequency $[r]>0.4$ ) and the remaining 17 loci were shown to be high-quality polymorphic markers (Table 1 and 2). For these 17 loci, the mean value of observed heterozygosity $\left(H_{0}\right)$ was very close to the expected heterozygosity $\left(H_{e}\right)$ with 0.422 and 0.420 , respectively. These polymorphic loci presented five to 14 alleles per locus, the observed and expected heterozygosity were ranged from 0.000 to 1.000 and from 0.000 to 0.798 , respectively (Table 2), when considering all three sampled populations. However, when considering only the largest sampled population (Litang County, $\mathrm{N}=100$ ), the polymorphic loci displayed four to 12 alleles per locus, the $\mathrm{He}$ and Ho showed values from 0.112 to 0.798 and from 0.093 to 0.980 , respectively. The Polymorphism Information Content (PIC) values ranged from 0.120 to 0.801 , with an average of 0.489 (Table 2). Among these polymorphic loci, three loci (TAMAR-103, TAMAR-116, andCMJ-214) displayed significant deviation from Hardy Weinberg equilibrium. Besides, we noticed that the loci showing a lack of polymorphism were limited to the studied populations with a small sampling size (Shangri la Town and Huguonongba populations) (Table 2).

In the last decade, microsatellite markers were used for studying the genetic diversity of junipers, such as J. thurifera $L$., J. phoenicea L., J. excelsa M. Bieb., and J. communis L. (MichalCzyk et al., 2006; Opgenoorth, 2009; Douaihy et al., 2011; Rumeu et al., 2012; Sertse et al., 2013; Bettencourt et al., 2015; Liu et al., 2019). Despite the ecological importance of J. squamata, no population genetic studies have been conducted to date. The 17 polymorphic SSR markers developed in this study will be very advantageous for these purposes.

However, the SSR markers reported in this study revealed a relatively low level of genetic diversity compared to other studies. For example, Michalczyk et al. (2006) developed five

Table 2

Genetic diversity of the 17 developed polymorphic microsatellite loci assessed across three populations of Juniperus squamata. The locus exhibiting null alleles was not included in this table. ${ }^{\text {a }}$

\begin{tabular}{|c|c|c|c|c|c|c|c|c|c|c|c|c|c|c|}
\hline \multirow[b]{2}{*}{ Locus } & \multicolumn{4}{|c|}{ Zhituo, Litang ( $N=100)$} & \multicolumn{4}{|c|}{ Shangrila, Daocheng $(N=6)$} & \multicolumn{4}{|c|}{ Huguonongba, Litang $(N=7)$} & \multicolumn{2}{|c|}{ Total $(N=113)$} \\
\hline & $\boldsymbol{A}$ & $A_{e}$ & $\boldsymbol{H}_{o}$ & $\boldsymbol{H}_{e}$ & $A$ & $A_{e}$ & $\boldsymbol{H}_{o}$ & $\boldsymbol{H}_{e}$ & $\boldsymbol{A}$ & $A_{e}$ & $\boldsymbol{H}_{o}$ & $\boldsymbol{H}_{e}$ & $\boldsymbol{A}$ & PIC \\
\hline HEX-25 & 5 & 1.942 & 0.421 & 0.485 & 3 & 1.674 & 0.167 & 0.403 & 3 & 1.556 & 0.413 & 0.357 & 8 & 0.569 \\
\hline FAM-26 & 8 & 3.375 & 0.636 & 0.704 & 4 & 2.057 & 0.333 & 0.514 & 3 & 2.649 & 0.413 & 0.622 & 8 & 0.651 \\
\hline FAM-36 & 5 & 1.410 & 0.213 & 0.291 & 1 & 1.000 & 0.000 & 0.000 & 1 & 1.000 & 0.000 & 0.000 & 5 & 0.250 \\
\hline HEX-43 & 4 & 1.401 & 0.283 & 0.286 & 2 & 1.180 & 0.167 & 0.153 & 2 & 1.508 & 0.429 & 0.337 & 5 & 0.264 \\
\hline HEX-65 & 7 & 1.126 & 0.093 & 0.112 & 1 & 1.000 & 0.000 & 0.000 & 3 & 1.342 & 0.286 & 0.255 & 8 & 0.116 \\
\hline HEX-68 & 8 & 1.415 & 0.283 & 0.293 & 4 & 2.400 & 0.500 & 0.583 & 2 & 1.153 & 0.143 & 0.133 & 10 & 0.286 \\
\hline FAM-71 & 4 & 1.148 & 0.135 & 0.129 & 2 & 1.180 & 0.167 & 0.153 & 1 & 1.000 & 0.000 & 0.000 & 5 & 0.120 \\
\hline $\begin{array}{r}\text { HEX-77 } \\
\text { TAMAR- }\end{array}$ & 7 & 1.423 & 0.230 & 0.297 & 4 & 1.714 & 0.500 & 0.417 & 3 & 1.556 & 0.429 & 0.357 & 8 & 0.424 \\
\hline $\begin{array}{c}103 \\
\text { TAMAR- }\end{array}$ & 8 & 3.480 & 0.717 & $0.713^{*}$ & 3 & 1.674 & 0.333 & 0.403 & 3 & 2.085 & 0.714 & 0.520 & 8 & 0.654 \\
\hline 116 & 8 & 3.451 & 0.548 & $0.710^{*}$ & 3 & 2.182 & 0.333 & 0.542 & 3 & 2.390 & 0.714 & 0.582 & 8 & 0.673 \\
\hline $\begin{array}{l}\text { HEX-123 } \\
\text { TAMAR- }\end{array}$ & 11 & 4.952 & 0.750 & 0.798 & 4 & 3.273 & 0.667 & 0.694 & 4 & 2.579 & 0.714 & 0.612 & 13 & 0.801 \\
\hline 134 & 10 & 3.627 & 0.687 & 0.724 & 3 & 2.571 & 0.833 & 0.611 & 1 & 1.000 & 0.000 & 0.000 & 10 & 0.659 \\
\hline CMJ-206 & 10 & 3.746 & 0.724 & 0.733 & 4 & 2.880 & 0.667 & 0.653 & 3 & 1.782 & 0.429 & 0.439 & 11 & 0.702 \\
\hline CMJ-214 & 11 & 2.472 & 0.980 & $0.595 *$ & 4 & 2.769 & 1.000 & 0.639 & 2 & 2.000 & 1.000 & 0.500 & 11 & 0.500 \\
\hline CMJ-230 & 8 & 3.085 & 0.667 & 0.676 & 4 & 2.880 & 0.833 & 0.653 & 3 & 1.556 & 0.429 & 0.357 & 8 & 0.628 \\
\hline CMJ-231 & 12 & 2.178 & 0.535 & 0.541 & 4 & 2.400 & 0.500 & 0.583 & 3 & 1.782 & 0.429 & 0.439 & 14 & 0.526 \\
\hline CMJ-241 & 8 & 2.127 & 0.596 & 0.530 & 4 & 3.130 & 0.667 & 0.681 & 3 & 1.342 & 0.286 & 0.255 & 9 & 0.485 \\
\hline Mean & 7.611 & 2.492 & 0.482 & 0.492 & 3.056 & 2.116 & 0.426 & 0.427 & 2.556 & 1.663 & 0.357 & 0.340 & 8.765 & 9.143 \\
\hline
\end{tabular}

Note: $N=$ sample size; $A=$ number of alleles; $A_{e}=$ effective number of alleles; $H_{o}=$ observed heterozygosity; $H_{e}=$ expected heterozygosity.

$P I C=$ Polymorphic information content

* Deviation from Hardy-Weinberg equilibrium $(P<0.05)$.

${ }^{a}$ Locality and voucher information are provided in Appendix 1. 
polymorphic nuclear SSR for J. communis, where the number of alleles per locus ranged from nine to 23 and the expected heterozygosity $\left(H_{\mathrm{e}}\right)$ ranged from 0.693 to 0.948 . In addition, Zhang et al. (2008) reported nine polymorphic nuclear SSR for J. przewalskii Kom., the number of alleles per locus ranged from three to six, and the expected heterozygosity $\left(H_{\mathrm{e}}\right)$ ranged from 0.58 to 0.70 across loci. For J. tibetica, 10 polymorphic nuclear SSR markers were developed; presenting two to 15 alleles per locus $(A)$, and expected heterozygosity $\left(H_{\mathrm{e}}\right)$ ranged from 0.20 to 0.90 across loci (Opgenoorth, 2009). Geng et al. (2017) developed eight nuclear SSR for J. sabina, where alleles per locus ranged from two to 27 and expected heterozygosity $\left(H_{\mathrm{e}}\right)$ ranged from 0.276 to 0.939 . The relatively low genetic diversity found in this study for J. squamata would be related to a recent bottleneck and range expansion of this species. However, further demographic analyses are needed to test this hypothesis.

Besides, these markers showed successful cross-amplification in studied individuals belonging to J. tibetica (17/17 SSR loci) and J. salutaria (15/17 SSR loci) (Table 3). The successful transferability of nearly all developed SSR markers from J. squamata to these species may be explained by their phylogenetic closeness (same clade in section Sabina (Miller) Spach)) (Mao et al., 2010; Adams, 2014). In general, the transferability of SSR markers among Juniperus studied species has been found to be relatively limited. However, in these studies, the crossamplification was tested between species separated phylogenetically, either from different sections or from different clades (Douaihy et al., 2011; Sertse et al., 2013; Bettencourt et al., 2015). This limitation could be due to the deviance in the genomic structure of non-close species (Sertse et al., 2013). In this study, we proved that the transferability of SSR markers in Juniperus could be very successful while dealing with closely related species.

\section{Conclusion}

We developed 17 polymorphic EST-SSR markers for J. squama$t a$, and at least 15 of which were transferable to $J$. tibetica and $J$. salutaria. These markers will promote further investigations to assess the genetic variation pattern of J. squamata. This study opens new avenues towards the development of forest management strategies for these juniper species.

Table 3

Characterization of the 17 developed EST-SSR markers for J. squamata in two closely related species $^{\mathrm{a}}$.

\begin{tabular}{|c|c|c|c|c|c|c|c|c|c|}
\hline \multirow{2}{*}{ Locus } & \multicolumn{4}{|c|}{ Juniperus tibetica $(\mathrm{N}=11)$} & \multicolumn{4}{|c|}{ Juniperus saltuaria $(\mathrm{N}=13)$} & \multirow{2}{*}{$\operatorname{Ta}\left({ }^{\circ} \mathrm{C}\right)^{\mathrm{a}}$} \\
\hline & $\boldsymbol{A}$ & $A_{\mathrm{e}}$ & $\boldsymbol{H}_{\mathbf{0}}$ & $\boldsymbol{H}_{\mathrm{e}}$ & $\boldsymbol{A}$ & $A_{\mathrm{e}}$ & $\boldsymbol{H}_{\mathbf{o}}$ & $\boldsymbol{H}_{\mathrm{e}}$ & \\
\hline HEX-25 & 3.000 & 1.906 & 0.455 & 0.475 & 4.000 & 2.380 & 0.462 & 0.580 & 55 \\
\hline FAM-26 & 3.000 & 1.847 & 0.636 & 0.459 & - & 一 & - & - & 55 \\
\hline FAM-36 & 1.000 & 1.000 & 0.000 & 0.000 & 4.000 & 2.315 & 0.308 & 0.568 & 55 \\
\hline HEX-43 & 3.000 & 1.449 & 0.364 & 0.310 & - & - & - & - & 55 \\
\hline HEX-65 & 4.000 & 1.984 & 0.364 & 0.496 & 1.000 & 1.000 & 0.000 & 0.000 & 55 \\
\hline HEX-68 & 5.000 & 1.820 & 0.545 & 0.450 & 4.000 & 1.380 & 0.231 & 0.275 & 55 \\
\hline FAM-71 & 1.000 & 1.000 & 0.000 & 0.000 & 1.000 & 1.000 & 0.000 & 0.000 & 55 \\
\hline $\begin{array}{l}\text { HEX-77 } \\
\text { TAMAR- }\end{array}$ & 4.000 & 1.766 & 0.545 & 0.434 & 5.000 & 2.793 & 0.692 & 0.642 & 57 \\
\hline $\begin{array}{c}103 \\
\text { TAMAR- } \\
116\end{array}$ & 5.000 & 3.408 & 0.273 & 0.244 & 3.000 & 1.888 & 0.615 & 0.470 & 53 \\
\hline $\begin{array}{c}\text { HEX-123 } \\
\text { TAMAR- } \\
134\end{array}$ & 6.000 & 3.103 & 0.727 & 0.678 & 5.000 & 2.641 & 0.615 & 0.621 & 55 \\
\hline CMJ-206 & 5.000 & 1.635 & 0.455 & 0.388 & 3.000 & 1.266 & 0.231 & 0.210 & 55 \\
\hline СМJ-214 & 3.000 & 2.180 & 0.909 & 0.541 & 7.000 & 4.829 & 1.000 & 0.793 & 55 \\
\hline CMJ-230 & 3.000 & 1.582 & 0.455 & 0.368 & 5.000 & 3.314 & 0.538 & 0.698 & 55 \\
\hline CMJ-231 & 4.000 & 1.467 & 0.364 & 0.318 & 4.000 & 3.219 & 0.462 & 0.689 & 55 \\
\hline CMJ-241 & 2.000 & 1.936 & 0.636 & 0.483 & 2.000 & 1.080 & 0.077 & 0.074 & 53 \\
\hline
\end{tabular}

Note: - failed amplification; $N=$ sample size; $A=$ number of alleles; $A_{\mathrm{e}}=$ effective number of alleles; $H_{0}=$ observed heterozygosity; $H_{\mathrm{e}}=$ expected heterozygosity

a Locality and voucher information are provided in Appendix 1. 


\section{Acknowledgement}

This work was supported by the National Natural Science Foundation of China (grant numbers 31622015) and Sichuan University (Fundamental Research Funds for the Central Universities, SCU2019D013, SCU2020D003).

\section{References}

Adams RP (2014) Junipers of the world: the genus Juniperus. Bloomington, Indiana, U.S.A.: Trafford Publishing. pp: 290-291. ISBN:978-1409723259.

Ashrafi H, Hill T, Stoffel K, Kozik A, Yao JQ, Chin-Wo SR, Deynze AV (2012) De novoassembly of the pepper transcriptome (Capsicum annuum): a benchmark forin silicodiscovery of SNPs, SSRs and candidate genes. BMC Genomics 13:571. https://www.biomedcentral.com/1471-2164/13/571

Bettencourt SX, Mendonça D, Lopes MS, Rocha S, Moniardino P, Monteiro L, Machado CA (2015) Genetic diversity and population structure of the endemic Azorean juniper, Juniperus brevifolia (Seub.) Antoine, inferred from SSRs and ISSR markers. Biochemical Systematics and Ecology 59:314-324. https://doi.org/10.1007/s10709-009-9416-5

Chen Y, Zeng Hui. (2015) Study on the plant diversity of the Sabina squamata community in Jiaozishan National Nature Reserve. Guizhou Forestry Science and Technology 43(02):10-14. https://doi.org/10.16709/j.cnki.gzlykj.2015.02.001

Chunco AJ (2014) Hybridization in a warmer world. Ecology and Evolution 4(10):2019-31. https://doi.org/10.1002/ece3.1052

Dakin EE, Avise JCJH (2004) Microsatellite null alleles in parentage analysis. Heredity 93: 504-509. https://doi.org/10.1038/sj.hdy.6800545

Douaihy B, Vendramin GG, Boratynski A, Machon N, Kharrat MBD (2011) High genetic diversity with moderate differentiation in Juniperus excelsa from Lebanon and the eastern Mediterranean region. AoB Plants 2011: plr003. https://doi.org/10.1093/aobpla/plr003

Doyle JJ, Doyle JL (1987) A rapid DNA isolation procedure for small quantities of fresh leaf tissue. Phytochemical Bulletin 19: 11-15.

Farjon A (2005) A monograph of Cupressaceae and Sciadopitys. Kew (United Kingdom): Royal Botanc Gardens Pages:382-386. ISBN: 978-1842460689.

Geng QF, Qing H, Ling ZR, Jeelani N, Yang J, Yoshikawa K, Miki NH, Wang ZS, Lian $\mathrm{CL}$ (2017) Characterization of polymorphic microsatellite markersfor a coniferous shrub Juniperus sabina (Cupressaceae). Plant Species Biology 32: 252255.

Gómez JM, González-Megías A, Lorite J, Abdelaziz M, Perfectti F. (2015) The silent extinction: climate change and the potential hybridization-mediated extinction of endemic high-mountain plants. Biodiversity and Conservation 24 (8):1843-57. https://link.springer.com/article/10.1007/s10531-015-0909-5

Grabherr MG, Haas BJ, Yassour M, Levin JZ, Thompson DA, Amit I, Adiconis X, Fan L, Raychowdhury R, Zeng QD, Chen ZH, Mauceli E, Hacohen N, Gnirke A, Rhind N, Palma FD, Birren BW, Nusbaum C, Toh KL, Friedman N, Regev A (2011) Full-length transcriptome assembly from RNA-Seq data without a reference genome. Nature Biotechnology 29: 644-652.

Jiang DC, Wu GL, Mao KS, Fang JJ (2015) Structure of genetic diversity in marginal populations of black poplar (Populus nigra L.). Biochemical Systematics and Ecology 61: 297-302. https://doi.org/ 10.1016/j.bse.2015.06.014

Klonner G, Dullinger I, Wessely J, Bossdorf O, Carboni M, Dawson W, EssI F, Gattringer A, Haeuser E, Van Kleunen M (2017) Will climate change increase hybridization risk between potential plant invaders and their congeners in Europe? Diversity and Distributions 23 (8):934-43. https://doi.org/10.111/ddi.12578

Li X-Y, Lin X-Y, Ruhsam M, Chen L, Wu M-Q, Thomas P, WenY-F (2019) Development of microsatellite markers for the critically endangered conifer Glyptostrobus pensilis (Cupressaceae) using transcriptome data. Silvae Genetica 68: 41-44. https://doi.org/10.2478/sg-2019-0007

Liu ZH, Kuang S, Qing ML,Wang DM, Li DW (2019) Metabolite profiles of essential oils and SSR molecular markers in Juniperus rigida Sieb. et Zucc. from different regions: A potential source of raw materials for the perfume and healthy products. Industrial Crops and Products 133: 424-434.

https://doi.org/ 10.1016/j.indcrop.2019.03.034

Mao KS, Hao G, Liu JQ, Adams RP, Milne RI (2010) Diversification and biogeography of Juniperus (Cupressaceae): variable diversification rates and multiple intercontinental dispersals. New Phytologist 188: 254-272.

https://doi.org/10.1093/bioinformatics/btp670

Marshall TC, Slate J, Kruuk LEB, Pemberton JM (1998) Statistical confidence for likelihood-based paternity inference in natural populations. Molecular Ecology: 639-655. https://doi.org/10.1046/j.1365-294x.1998.00274.x

Meglecz E, Pech N, Gilles A, Dubut VC, Hingamp P, Trilles A, Grenier R, Martin JE (2014) QDDversion 3.1: a user-friendly computer program for microsatellite selection and primer design revisited: experimental validation of variables determining genotyping success rate. Molecular Ecology Resources 14 1302-1313. https://doi.org/10.1093/bioinformatics/btp670

Miah G, Rafii MY, Ismail MR, Puteh AB, Rahim HA, Islam KN, Latif MA (2013) A review of microsatellite markers and their applications in rice breeding programs to improve blast disease resistance. International Journal of Molecular Sciences 14:22499-22528. https://doi.org/doi:10.3390/ijms141122499

Michalczyk IM, Sebastiani F, Buonamici A, Cremer E, Mengel C, Ziegenha B, Vendramin GG (2006) Characterization of highly polymorphic nuclear microsatellite loci in Juniperus communis L. Molecular Ecology Notes 6: 346-348. https://doi.org/10.1111/j.1471-8286.2005.01227.x

Opgenoorth L (2009) Identification and characterization of microsatellite marker in the tetraploid Juniperus tibetica Kom. using next generation sequencing. Conservation Genetics Resources 1: 253-255. https://doi.org/10.1007/s12686-009-9062-3

Peakall R, Smouse PE (2012) GenAIEx 6.5: genetic analysis in Excel. Population genetic software for teaching and research--an update. Bioinformatics 28:2537-2539. https://www.ncbi.nlm.nih.gov/pubmed/22820204

Pauls, S. U., Nowak, C., Bálint, M., \& Pfenninger, M. 2012. The impact of global climate change on genetic diversity within populations and species. Molecular Ecology, 22(4), 925-946. https://doi.org/10.1111/mec.12152

Pepin N, Bradley RS, Diaz HF, Baraer M, Caceres EB, Forsythe N, Fowler H, Greenwood G,Hashmi MZ, Liu XD, et al( 2015) Elevation-dependent warming in mountain regions of the world. Nature Climate Change 5(5): 424-430. https://doi.org/10.1038/NCLIMATE2563

Qi WC, Lin F, Liu YH, Huang BQ, Cheng JH, Zhang W, Zhao H (2016) High-throughput development of simple sequence repeat markers for genetic diversity research in Crambe abyssinica. BMC Plant Biology 16:139. https://doi.org/10.1186/s12870-016-0828-y

Rozen S, Skaletsky H (2000) Primer3 on the WWW for General Users and for Biologist Programmers. In: Misener S, Krawetz SA (eds) Bioinformatics Methods and Protocols. Methods in Molecular Biology ${ }^{\mathrm{TM}}$ (vol 132). Totowa, New Jersey, U.S.A.: Humana Press. pp: 365-386. ISBN: 978-0896037328. https://doi.org/10.1385/1-59259-192-2:365

Rumeu B, Sosa PA, Nogales M, Perez MA-G (2012) Development and characterization of 13 SSR markers for an endangered insular juniper (Juniperus cedrus Webb \& Berth.). Conservation Genetics Resources 5: 457-459. https://doi.org/ 10.1007/s12686-012-9827-y

Sertse D, Gailing O, Eliades N-G, Finkeldey R (2013) Transferability and application of microsatellites (SSRs) from Juniperus communis L. to Juniperus procera Hochst. Ex endl. Open Journal of Genetics 03: 115-126. https://doi.org/10.4236/ojgen.2013.32015

Summers K, Amos W (1997) Behavioral, ecological, and molecular genetic analyses of reproductive strategies in the Amazonian dart-poison frog, Dendrobatesven rimaculatus. Behavioral Ecology 8: 260-267. https://doi.org/10.1016/0144-8188(95)00051-8

Thiel T, Michalek W, Varshney RK, Graner A (2003) Exploiting EST databases for the development and characterization of gene-derived SSR-markers in barley (Hordeum vulgare L.). In: (ed) Theoretical and Applied Genetics 106: 411 422. https://doi.org/10.1007/s00122-002-1031-0

Tsumura Y, Yoshimura K, Tomaru N, Ohba K (1995) Molecular phylogeny of conifers using RFLP analysis of PCR-amplified specific chloroplast genes. Theoretical and Applied Genetics 91:1222-1236 https://doi.org/10.1007/bf00220933

Untergasser A, Cutcutache I, Koressaar T, Ye J, Faircloth BC, Remm M, Rozen S G (2012) Primer3-new capabilities and interfaces. Nucleic Acids Research 40: e115-e115. https://doi.org/10.1093/nar/gks596 
Vallejo MM, Hiscock SJ (2016) Hybridization and hybrid speciation under global change. New Phytologist 211 (4):1170-87.

https://doi.org/10.1111/nph.14004

Vieira ML, Santini L, Diniz AL, Munhoz CF (2016) Microsatellite markers: what they mean and why they are so useful. Genetics and Molecular Biology 39: 312-328. http://dx.doi.org/10.1590/1678-4685-GMB-2016-0027

Zhang Q, Li J, Zhao YB, Korban S, Han YP (2012) Evaluation of genetic diversity in Chinese wild apple species along with apple cultivars using SSR Markers. Plant Molecular Biology Reporter 30: 539-546.

https://doi.org/10.1007/s11105-011-0366-6 